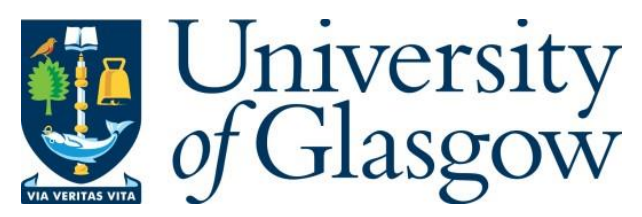

Palmer, V. J. (2018) Grandparents' contribution to a family culture of physical activity. Gerontologie et Societe, 40(156), I-XVI.

There may be differences between this version and the published version. You are advised to consult the publisher's version if you wish to cite from it.

http://eprints.gla.ac.uk/159507/

Deposited on: 23 March 2018

Enlighten - Research publications by members of the University of Glasgow

http://eprints.gla.ac.uk 


\title{
Grandparents' contribution to a family culture of physical activity
}

\author{
Victoria J. PALMER \\ Research Associate, Institute of Health and Wellbeing, College of Social Sciences, \\ University of Glasgow
}

\section{Résumé - Le rôle des grands-parents dans la formation d'une culture familiale en AP}

La famille est souvent identifiée comme jouant un rôle déterminant dans l'activité physique des seniors. Cependant, nous avons peu de détails sur la façon dont la vie de famille peut influencer les croyances, les compréhensions et les pratiques en matière d'activité physique lors du processus de vieillissement. Les améliorations de l'espérance de vie, notamment, ont mené à des changements dans la vie de famille, avec un nombre croissant de personnes côtoyant des membres de leur famille de plusieurs générations. Par conséquent, les familles bénéficient d'un plus grand nombre d'années de vie partagée. Cette variation dans la structure familiale peut influencer la manière de 'faire famille', c'est-à-dire les rôles et responsabilités qui constituent la vie de famille. Ainsi, il y a eu un intérêt croissant pour les relations entre générations dans les familles. Cependant, dans le domaine de l'activité physique, la recherche s'est concentrée sur deux générations. En outre, nous avons peu d'information sur la façon dont les relations entre les générations peuvent influencer les croyances, les compréhensions et les pratiques en matière d'activité physique, surtout celles concernant les séniors. Se reposant sur des données récoltées auprès des membres de trois générations dans cinq familles résidant dans l'ouest de l'Écosse, cet article montre en effet comment l'activité physique des seniors contribue à la construction d'une culture familiale en activité physique, renforçant ainsi les liens intergénérationnels.

Mots clés - Activité physique, vieillissement, vie de famille, grands-parents, relations intergénérationnelles

\begin{abstract}
Grandparents' contribution to a family culture of physical activity
Family is often identified as a determinant or correlate of older adults' physical activity. However, we know little about how family life can influence physical activity beliefs, understandings and practices as we age. Changes in life expectancy have resulted in changes in family life, with an increasing amount of families now living with multiple generations. As a result, families experience an increased number of years of shared lives. This shift in family structure may affect the way we do family, that is, what roles and responsibilities are undertaken as part of family life. Thus, in the last decade there has been an increasing interest in intergenerational relationships within families in the literature. However, in relation to physical activity, research in intergenerational families has focussed on two generational families. In addition, little is known about how intergenerational relationships may influence physical activity beliefs, understandings and practices, particularly from the perspective of older adults. Based on data from five three-generational families from the West of Scotland, results show how the physical activity practices of older people contribute to a family culture of physical activity, thus reinforcing intergenerational links.
\end{abstract}

Keywords - Physical activity, ageing, family life, grandparents, intergenerational relationships 


\section{$\underline{\text { Introduction }}$}

Physical activity is recognised as a global public health priority, particularly for older people. Since the 1990's evidence has increasingly linked being active in later life to reversing age-related deterioration of the cardiovascular system, reducing the rate, and delaying the onset of sarcopenia (age related loss of muscle mass) whilst maintaining bone strength (Taylor et al., 2004). Thus, physical activity is seen to postpone the onset of morbidity and ultimately to prolong life (Paterson, Jones \& Rice, 2007). As a result, policymakers and practitioners have focussed on attempts to engage older adults in physical activity, primarily through individual level interventions. However, the results of these have been varied, and a large proportion of older adults remain 'inactive'. In addition, throughout the latter half of the twentieth century, changes in life expectancy have resulted in an increased number of multigenerational families. Yet, the role that family may play in physical activity has tended to focus on younger generations, rather than in adults and older adults. In the latter half of the twentieth century there has been a rise in the number of families living with multiple generations increasing the number of 'years of shared lives' altering intergenerational dynamics within families (Bengston, 2001). This has been overlooked in research on older adults' physical activity, with research around family and older people's physical activity focussing on support from spouses (Dionigi, Fraser-Thomas \& Logan, 2012; Pettee et al, 2006; Stevenson, 2002; Tulle, 2008) without considering how changing family structures to 'beanpole' families (multiple living generations, with relatively even numbers in each generation) (Bengtson, 2001) may impact upon the relationships that are part of everyday family life (i.e. how we do family) and how these may influence physical activity.

Some research with master athletes has begun to expose how physical activity experiences are influenced by other generations within families, particularly from their children. This could be indirectly through allowing their parents to participate in physical activity in later life and offering encouragement and support (Dionigi \& al, 2012). Younger generations also provided support in more direct forms by attending competitions (Roper, Molner \& Wrisberg, 2003) or occasionally being active with their children (Dionigi et al, 2012). Some master athletes also noted that their involvement in sport often began through engagement in their children's sport participation, either by being inspired by their child's activity or re-engaging through coaching roles. Others observed that their children's physical activity encouraged them to maintain their previous physical activity levels in order to be fit enough to play with their children (Dionigi et al, 2012). However, there was very little discussion of grandchildren and what role they may play in physical activity in later life. This may be partly due to the fact that master athletes may be relatively young. One case study of an 88 year-old, highlighted the continued support of his family at competitions and events, including his grandchildren (Roper et al, 2003). One other example showed that grandparents' physical activity had to be negotiated around their role as a grandparent (i.e. caring responsibilities) (Grant, 2001). This suggests that, physical activity may impact upon or be played out through intergenerational relationships within families.

There have been very few studies that have explored intergenerational physical activity within families beyond parent-child physical activity. One study developed a physical activity intervention in threegenerational families, although results were based on measures of physical activity rather than exploring the relationships and dynamics of doing intergenerational physical activity (Ransdell et al, 2005). In addition, C. Phoenix and A. Sparkes (2006) explored how young athletes drew on narratives of their parents and grandparents to construct their understanding of ageing and being active in later life, however, they did not explore older adults' perspectives on intergenerational physical activity and relationships. Thus, this paper will explore intergenerational relationships further, with particular focus on how older adults are influenced by these relationships, as well as exploring intergenerational relationships, in relation to physical activity. It will also explore how older adults' physical activity may influence younger generations' physical activity practices by examining how dispositions towards physical activity are reproduced within families.

\section{Theoretical Perspective}

The lack of research focussing on physical activity in families may be in part due to the difficulty in understanding the intricacies of family life. Since family is part of our everyday lives, often aspects of family life become taken for granted. In addition, understandings of family are shaped by the social and cultural context in which we live (McKie, 2006), therefore, providing a definition of family is extremely 
difficult (Cheal, 2002). Thus, in order to understand more about how physical activity is negotiated in families we should focus less on what family is and more on what families do (Morgan, 1996, 2004, 2011a). To do this, we should consider family practices (Morgan, 1996, 2004, 2011a, 2011b), that is "the ordinary, everyday actions that people do, insofar as they are intended to have some effect on another family member" (Cheal, 2002. p.12). This approach focuses on the lived experiences of family lives and the roles and relationships performed within and by families (Morgan 1996, 2004, 2011a, 2011b). Family life is therefore a set of activities that constitute the experiences of everyday family living. Thus, they are not restricted to those in one household, or specific family members. Some family practices may be shared by a large proportion of the population (D. Morgan uses the example of the school run) (Morgan, 2011a). This highlights the flexibility and fluidity of family life. Family practices coexist with other aspects of life and often the overlaps and connections are of greater importance than each separate entity (Morgan, 2004). As such, family practices may not always be observed purely as family practices, they may be described as something else or may emerge when discussing other practices (physical activity, for example).

This work also draws on the theoretical toolkit of Pierre Bourdieu. P. Bourdieu's theory of practice examines the actions of everyday life, accepting that practice is not an accumulation of individual behaviour (Jenkins, 1992). For him, practice is a combination of the relationship between social and mental structures, and the production and reproduction of class groups and social hierarchies whereby the social world becomes self-evident and taken for granted (Bourdieu, 1977). For P. Bourdieu, this occurs through the interaction between internalised dispositions that are embodied as habitus, the economic, social, cultural and symbolic capital we possess and the social space or field in which practice occurs. Indeed, D. Morgan's understanding of family practices draws heavily on Bourdieu's work (Morgan, 2011b). Therefore, it is possible to explore how physical activity practices are performed within and by families, and whether these are performed as a way of doing family.

P. Bourdieu situates family within his work, recognising that family is in itself socially constructed. He views it as both a structuring structure and a structured structure, which is perhaps the most natural of social categories creating a model for other social bodies (Bourdieu, 1996). Thus family is aligned with habitus but can function as a field. He also notes how families play a key role in social reproduction. That is, the reproduction of (dominant) social structures within a social group. This is because habitus is first acquired within families (Bourdieu, 1977). In addition, each generation intends to transmit the advantage it holds in society to the next through reproduction strategies (Bourdieu, 1973). The effectiveness of the reproduction strategy is dependent on the value placed on the specific composition of capital within the family's social group (Bourdieu, 1973). Physical activity, therefore, may be viewed as a reproductive strategy i.e. a legitimate practice that is worth investing in (economic capital in the form of time and money) and holds specific benefits to the next generation through the accumulation of capital (physical and social). The specific value that physical capital holds as a reproductive strategy, is determined firstly within the family (as the family functions as a field) and secondly in relation to a family's social location.

Grandparents' may play a key role in the social reproduction of physical activity in families through the downward transmission of capital within families. In addition, since dispositions are first created within families, they could inform the creation of shared dispositions towards physical activity within families (i.e. a family habitus). To understand how this may occur, it is important to consider what may have influenced older adults' own dispositions towards physical activity. P. Bourdieu's work emphasises the role of social location in creating and reproducing dispositions which is reflected in the treatment of the body, including how we choose to put our bodies into movement. The middle classes are often seen to nurture the body and are more likely to reproduce the culture of health and anti-ageing that is currently associated with physical activity practices (Bourdieu, 1984). However, while physical activity is currently linked with public health, this has not always been the case (Stone, 2004), and promotion of physical activity for health only emerged in the late 1990s. Therefore, older adults dispositions towards physical activity may not be influenced by the current dominant discourse of health, wellbeing and anti-ageing.

Drawing on the work of D. Morgan and P. Bourdieu, this research aims to explore two aspects of older adults' physical activity within families. Firstly, it sets out to how older adults' physical activity is shaped by family life, particularly intergenerational relationships within families. Secondly, it explores the role that grandparents may play in shaping future generations' physical activity dispositions by exploring whether grandparents' physical activity contributes to social reproduction within families. Addressing the following research questions: 
1. How are older adults' physical activity practices shaped by doing intergenerational relationships within families?

2. Do older adults contribute to social reproduction of physical activity dispositions within families?

\section{Methodology}

This paper draws on qualitative data from a qualitative-led mixed methods project exploring beliefs, understandings and practices of physical activity in three generational families. Data collection occurred in three stages; firstly, each participant took part in an in individual interview designed to provide detailed accounts of participants lived experiences of physical activity. The interview was followed by a sevenday period of objective physical activity monitoring using an activPAL ${ }^{T M}$ device, which was used to identify familial patterns of physical activity, provide an objective measure of physical activity and contextualise the individual data. The final stage involved a group interview (family discussion) which aimed to capture the relationships that contribute to negotiating physical activity in families and to allow participants to reflect on their objective physical activity data.

\section{Participants}

Five three-generational families were recruited using purposive (through physical activity classes [ $\mathrm{N}=2]$ ) and snowball sampling using participants' own networks $(\mathrm{N}=3)$ methods. Participants were not required to be physically active to take part, however all participants self-identified as physically active. At least one child, one parent and one grandparent (direct descendants) from each family participated in the research. An outline of the participating families can be seen in table 1. All of the families were from low-middle/middle class background based on occupation (or previous occupation for those who were retired) categories in the National Statistics Socio-economic Classifications (Rose and Prevalin, 2005). All of the families were two parent families ${ }^{1}$. This research will focus on the grandparents' experiences of physical activity and family life.

\begin{tabular}{|c|c|c|c|c|c|c|}
\hline & Family 1 & Family 2 & Family 3 & Family 4 & & Family 5 \\
\hline $\begin{array}{l}\text { Grandparent Sex, } \\
\text { Age } \\
\text { Marital Status } \\
\text { No. Children }\end{array}$ & $\begin{array}{l}\text { Katherine } \\
\mathrm{F}, 59 \\
\text { Married } \\
2 \text { children }\end{array}$ & $\begin{array}{l}\text { Donald M, } \\
68 \\
\text { Married } \\
2 \text { children }\end{array}$ & $\begin{array}{l}\text { Jim M, } \\
79 \\
\text { Married } \\
3 \text { children }\end{array}$ & $\begin{array}{l}\text { Elaine } \\
\text { F, } 62 \text { Married } \\
3 \text { children }\end{array}$ & & $\begin{array}{l}\text { Mary } \\
\mathrm{F}, 71 \\
\text { Widowed } \\
2 \text { children }\end{array}$ \\
\hline $\begin{array}{l}\text { Adult Child } \\
\text { Sex, Age } \\
\text { Marital Status } \\
\text { No. Children }\end{array}$ & $\begin{array}{l}\text { Faye } \\
\mathrm{F}, 39 \\
\text { Married } \\
1 \text { child }\end{array}$ & $\begin{array}{l}\text { Stuart } \\
\mathrm{M}, 34 \\
\text { Married } \\
2 \text { children }\end{array}$ & $\begin{array}{l}\text { Sheila } \\
\mathrm{F}, 45 \\
\text { Married } \\
3 \text { children }\end{array}$ & $\begin{array}{l}\text { Arlene } \\
\text { F, } 40 \\
\text { Co-habiting } \\
3 \text { children }\end{array}$ & & $\begin{array}{l}\text { Liz } \\
\mathrm{F}, 47 \\
\text { Married } \\
2 \text { children }\end{array}$ \\
\hline $\begin{array}{l}\text { Grandchild(ren) } \\
\text { Sex, Age }\end{array}$ & $\begin{array}{l}\text { Melissa } \\
\mathrm{F}, 13\end{array}$ & $\begin{array}{l}\text { Aimee } \\
F, 10\end{array}$ & $\begin{array}{l}\text { Jack } \\
\text { M, } 12\end{array}$ & $\begin{array}{l}\text { Sarah } \\
F, 18\end{array}$ & $\begin{array}{l}\text { Caitlin } \\
F, 11\end{array}$ & $\begin{array}{l}\text { Grant } \\
\mathrm{M}, 16\end{array}$ \\
\hline
\end{tabular}

Table 1: Detailed characteristics of the five participating families.

All of the grandparents were retired or semi-retired (Donald). Four were married and one (Mary) was recently widowed. None of the grandparents lived with younger generations of their family. However, grandparents stayed in the same town as (Katherine, Elaine, and Mary) or a nearby town to (Donald and $\mathrm{Jim}$ ) their participating children and grandchildren. Some of the grandparents played a key role in their grandchildren's care by taking children to and from school or watching their grandchildren while their adult children were working. However, none of these grandparents provided 'formal' or 'full-time' care for their grandchildren.

\section{Data Collection}

${ }^{1}$ Family 1 parent and stepparent family, family 4 cohabiting parents, family 5 grandparent was recently widowed. 
The qualitative elements of this research were designed to capture participants' lived experiences of physical activity and family life. Individual interviews (17 in total) were developed based around three areas: background information, physical activity and family life. Questions were open ended to allow flexibility for discussion based on participants' responses. In addition, the interviews contained elements of life history in their design (Josselson and Lieblich, 1995). This was included to capture how beliefs, understandings and practices of physical activity developed or changed over the participants' lifecourse. Since a broader aim of the project was to capture understandings of physical activity, participants were not given any pre-defined definitions of physical activity. Participants were asked to provide their own understanding of physical activity, and to identify their own physical activity practices. Individual interviews lasted between 16 and 40 minutes. They were designed to be relatively short whilst eliciting rich data. This was due to the nature of data collection as all the interviews within each family were conducted in the same session at the convenience of the participants.

Following the objective physical activity monitoring, participating members of each family took part in a family discussion $(\mathrm{N}=5)$. Participants' physical activity data from the activPAL ${ }^{\mathrm{TM}}$ monitor was used to stimulate discussion. Using data prompts in interviews stimulates and guides discussion, giving participants an opportunity to see the data and to discuss their views of the data presented (Kwasnicka et al., 2015). The interviews were semi-structured and covered four general themes: the experience of wearing the activPALTM, patterns of physical activity, individual physical activity and physical activity compared with physical activity recommendations. Having all the participating family members take part in the family discussions afforded an opportunity to explore some family dynamics, and to tease out the relationships that contribute to negotiating physical activity within families. It is often the case in family research that including multiple family members within the research process allows a deeper understanding of the relationships which prevail. Family discussions lasted between 1 hour and 1 hour and 30minutes.

Data were collected over a one-year period. Due to the three-stage research design, data collection took an average of four weeks to complete. All interviews were audio recorded. Individual interviews were transcribed verbatim and group interviews were selectively transcribed by the researcher. Both individual and group interview data were analysed thematically (Braun and Clark, 2006).

\section{Findings}

The findings presented in the following sections address each research question in turn starting with the how grandparents' physical activity practices were shaped by doing intergenerational relationships. Following from this I will explore whether they contributed to the social reproduction of physical activity dispositions within their families.

\section{Generations active together}

Physical activity was not generally considered by the participants to be a 'family activity', despite all of the participants engaging in regular physical activity practices. Among the participating families there was a sense of closeness and spending time with family was viewed as important: any time I can I spend with the family as I say it is important (Donald, aged 68, Family 2)

However, physical activity was rarely associated with 'family time'. Instead family time was associated with more sedentary activities, such as eating a meal. Nevertheless, it was clear that physical activity practices were negotiated between multiple family members and across generations. Thus, negotiating physical activity was carried out in relation to family roles as parents or grandparents.

A unique insight from this work was the observations of relationships between grandparents, grandchildren and physical activity. Some grandparents and grandchildren were active together. The types and frequencies of physical activities that grandparents and their grandchildren participated in were varied, but what emerged was that physical activity constituted part of their role as a grandparent. As such, physical activities were often performed when grandparents assumed caring roles for their grandchildren, such as after school or during school holidays. For some grandparents, such as Donald, 
aged 68 (family 2) looking after grandchildren provided new opportunities to be active. Others like Jim, aged 79 , (family 3 ) utilised physical activity as an opportunity to create shared interests with their grandchildren while caring for them. For Jim this was something that he particularly valued as he had not been able to do this with his other grandchildren as they had not lived nearby when they were younger. These relationships highlight that while physical activity is not necessarily a 'family activity', it is deeply embedded in family life. As such, physical activity can be utilised to build on roles and relationships within families.

As well as finding opportunities to be active with their grandchildren, some of the grandparents drew on their relationships with grandchildren either as new opportunities to participate in physical activity or as motivation to participate in physical activity. For example, Elaine, aged 62 (family 4) finds motivation to be active through her younger grandchildren:

VP: And do you think that your grandchildren's PA influences yours now?

Elaine: It does because I like to be able to keep myself fit so that I can still keep up with them like you know

VP: $M m h m m$

Elaine: Don't want to be lagging behind them [laughs] sitting in the park saying no I can't play football l'm too old [laughs]'

In this case, Elaine uses her grandchildren to shape her physical activity highlighting the importance of intergenerational relationships within families.

In addition to relationships with grandchildren, relationships with adult children also influenced grandparents' experiences of physical activity in later life. Adult children often facilitated their parents' physical activity and imparted their physical activity beliefs to their parents. Facilitation of physical activity took the form of providing opportunities to be active. For example, Mary's (aged 71, family 5) opportunity to be active is created through walking her daughter's dog. She states 'I walk the dog for Liz at lunchtime' and then explains that 'the dog, he's the only exercise I really have'. In other cases this was by being active together as Katherine, aged 59 (family 1) states:

'I mean they'll [daughters and granddaughter] come up...Faye [my daughter] will phone up "right mum were going up the braes [hills] do you want to come up?" you know we go up with the dogs, if they didn't do that I would never think about going up myself, you know "we're going to [the seaside] do you want to come?" that kind of thing'.

Moreover, adult children pro-actively transmitted their beliefs and understandings of physical activity to the grandparents. Often taking the form of a 'gentle-nudge':

'from [Stuart, my son] l'm getting "oh you'll be able to do a bit of walking when you're away this week you know?" Eh, Nice and gentle but what he's really saying is you need to do a bit more exercise dad' (Donald, aged 68, family 2)

This pro-active transmission contributed to the maintenance of a family culture of physical activity which meant that grandparents were supported (by being allowed) to be active in later life.

These findings suggest that physical activity practices emerge as a way of doing family through being active with younger generations. However, intergenerational relationships also continue to shape older adult' dispositions towards their own physical activity practices in later life, through receiving support, and drawing motivation, from younger generations within families.

\section{Shaping the future: Grandparents' role in family cultures of physical activity}

There were particular cultures of physical activity that were evident in the presence of shared beliefs, understandings and practices of physical activity within each family. Grandparents played a key role in shaping these family cultures of physical activity by laying the groundwork for creating future generations. This downward transmission was often recognised by adult children. Some acknowledged a direct influence as Arlene, aged 40 (Family 4) notes how her physical activity echoes her mother's:

'...I think I'm probably quite like my mum [laughs] my mum never sat still she walked everywhere and I probably followed in her footsteps' 
Other parents appear to be less directly influenced by their parents' own activities but more by the encouragement, support and opportunities their parents gave them, as Stuart, aged 34, Family 2, remarks:

I suppose looking back my parents gave me opportunities to go and be involved in physical activity so they probably had a role in shaping my attitudes towards being active'

Likewise, Sheila, aged 45 (family 3) notes 'I don't know if they [parents] influence me now but I know that the influence that they had over me when I was younger probably still has an influence on how I behave now [in relation to physical activity]'

In some cases this downward transmission was recognised through active identities i.e. they were part of a sporty or active family, as Liz, aged 45 (family 5) points out 'I was brought up in a sporty family', she then discusses this further when she was asked about factors that influence physical activity. Note how often she uses 'sporty' to describe herself and other family members:

'No I think it's your family [that influence physical activity] my mum and dad were sporty, my dad ran like football teams things like that [...] so there always sort of ...there was always like a sporty aspect there and so I think...I think part of that is but then part of it is I think an individual thing because I'm thinking about other ones that I know...like [my husband] and his brother I know I shouldn't talk about him but I'm just thinking how it, l'm thinking...he's sporty but his brother's not but for me I enjoyed sport I was good at it and but I was always brought up in a household that was sort of some type of sport because my brother was the same he's sporty as well'

This supports the idea that our early experiences of physical activity are shaped by our family and that these are carried with us throughout our lives. Thus, we observe a degree of investment from the grandparents' to ensure their children created dispositions towards physical activity, legitimising physical activity as a worthwhile practice.

The grandparents themselves highlight this investment in their children's physical activity, particularly as their children were growing up. They recognise that they provided support and encouraged their children to be active when they were younger, highlighted here:

'Well as a [young] family I was always very keen that the children get involved [in physical activity]' (Jim, Aged 79, Family 3)

'Well we always encouraged the boys to be physically active when they were younger' (Donald, Aged 69, Family 2)

Interestingly, none of the grandparents talk about their parents as being influential in the same way. One grandparent, Katherine, aged 59 (family 1) talked about her mother who influenced her current physical activity as she visited three times a week to do her housework ${ }^{2}$ as her mother was no longer able, but none of the other grandparents mentioned their parents in relation to physical activity. Suggesting that family cultures of physical activity may have begun with the grandparents' generation. There may be several explanations for this. Perhaps it relates to the changing nature of physical activity historically or it may simply be due to the nature of the research, with more focus placed on the relationships between physical activity and the other participating family members.

Some of the grandparents also felt that they influenced their grandchildren's physical activity, mostly through facilitating it. Jim, aged 79 (family 3 ) talks about playing golf with his grandson, and buying his other grandchildren golf clubs. Similarly, Elaine, aged 62, (family 4) discusses how she takes her younger grandchildren to the park regularly to play football and 'catch'. Other grandparents, such as Mary, aged 71, family 5, believed it was a 'knock on thing', she felt she did not directly influence her grandchildren but '...

encourage[d] my own children and they are now doing what...my husband and I encouraged ours to do they're now doing it for their own family'. Jim, aged 79 (family 3), also alludes to this: 'I think families grow like father like son'.

Only three of the grandchildren recognised their grandparents as influential in their own physical activity. Interestingly, two of them were the girls from family 4. For them their 'Nana'3 (Elaine) was a physical activity role model as her granddaughter Sarah (aged 18) explains

\footnotetext{
${ }^{2}$ Housework, alongside walking, was a main contributor to Katherine's physical activity

${ }^{3} \mathrm{Nana}$ is short for grandmother.
} 
‘... my Nana, like she’s actually like...the fittest person I know'.

Sarah and her sister both noted that their 'Nana' walked everywhere and that it had impacted on their own physical activity as they would often spend time with her and were expected to walk too. The other child who recognised his grandparents as influences on his physical activity was Jim's (aged 79, family 3) grandson Jack (aged 12) who noted that this was through practices, as he played golf with Jim and went walking with his grandmother. This highlights the longstanding influence of the grandparents on these family cultures of physical activity through their own continued investment of capital in the younger generations, but also through creating, and reproducing shared dispositions towards physical activity.

In these families, the presence of a family culture of physical activity suggests that physical activity dispositions are reproduced within families. Grandparents appear to play a key role in this, particularly through the investment in their children and grandchildren's physical activity. This was recognised and embodied by the younger generations through shared dispositions and practices of physical activity.

\section{Discussion}

Until now, the role family plays in establishing and maintaining physical activity in later life has been overlooked in the physical activity literature. This research aimed to explore how older adults' physical activity is shaped by family life, and in turn how older adults' physical activity can influence their families' dispositions towards being active. For these families, physical activity was part of family life, not as a 'family activity' per se, but through roles and relationships within families i.e. a way of doing family. For grandparents, this was particularly clear in connecting with their grandchildren through performing physical activity together, and drawing motivation to be active from their grandchildren. The grandparents also played a key role in establishing family cultures of physical activity in these families, contributing to the social reproduction of dispositions towards physical activity through downward transmission of physical activity beliefs.

Being active together may act as a means to perform and strengthen intergenerational relationships between children and grandparents through shared routines (after school care, for example) and interests (physical activity practices) (Ross et al., 2005). In these families, informal caring roles often presented opportunities for grandparents to be active with their grandchildren. Previous research shows that families often draw on grandparents to provide informal care, with grandparents thought to provide around a quarter of total childcare for working families (Gray, 2005). This may be particularly relevant as people are living longer (and are healthier) than previous generations, contemporary families experience more years of shared lives (Bengtson, 2001). Additionally, while formal childcare has increased in availability, it is costly (particularly in the UK (Gray, 2005)), and grandparents are often viewed as 'the next best thing' if parents themselves cannot provide care (Wheelock \& Jones, 2002). The grandparents also drew motivation to be active from their grandchildren in order to be able to fulfil their role as a grandparent. Both examples emphasise the potential for exploring physical activity as a means of strengthening, developing and doing intergenerational relationships between grandchildren and grandparents. To date there has been very little research that has explored intergenerational physical activity between grandparents and grandchildren within families. Additionally, research on intergenerational physical activity within families have tended to focus on the experiences of younger generations rather than those of older adults. Thus, more work is needed to explore how intergenerational relationships may be fostered through physical activity within families, particularly from the perspective of older adults.

In addition to intergenerational relationships with grandchildren, the grandparents' relationships with their adult children also fostered physically active practices. Not unlike the master athletes in R. Dionigi et al's (2012) work, children offered support through 'allowing' their parents to remain physically active as they got older. However, in these families support was not only through encouragement, but also through facilitating the grandparents' physical activity by providing opportunities to be active. This appeared to be upward transmission of physical activity in order to ensure that grandparents' dispositions towards physical activity were aligned with their own. This investment from adult children is likely owed to a high level of engagement with public health messages that emphasise the role of physical activity for prolonging life, and quality of life, among this generation (Palmer, 2015). While it is unclear from my work what underpins the motives for upward transmission, a greater number of years 
of functional independence for grandparents would mean families would experience greater number of years of shared lives. As such, adult children's motives may be altruistic. However, this also means that grandparents can continue with caring responsibilities for grandchildren, and it reduces the likelihood of grandparents requiring care from their children.

While intergenerational physical activity and support for grandparents' physical activity were observed in these families, it is important to consider the conditions under which these relationships exist. There were cultures of physical activity that were present in all of these families. These were indicative of a 'family habitus' and reinforce Bourdieu's notion that habitus is created within families (Bourdieu, 1977). In addition, the presence of shared beliefs, understandings and practices of physical activity across all three generations indicates that dispositions towards physical activity are reproduced in families. This work highlights that grandparents played a key role in establishing these family cultures of physical activity and these in turn can be aligned to normative discourses of physical activity which prevail at various historical points. However, it is the reproduction of these family cultures of physical activity that support older adults to engage with physical activity as they age. Without these shared dispositions which are in alignment with contemporary discourses of physical activity, families may hold conflicting ideas about physical activity and ageing.

As well as the presence of family cultures of physical activity, specific expressions of doing family were prevalent in all these family. These families expressed a sense of 'closeness' as a family, in that they placed importance on particular aspects of family life. As a result, they invested in spending time with family members allowing intergenerational relationships to flourish. As S. Shaw and D. Dawson (2001) have previously noted family leisure (such as physical activity) is particularly valued for developing this sense of closeness, as it indicates responsibility and commitment to family life, and this was expressed through families fulfilling roles through being active together. However, this was helped by a geographical closeness which meant grandparents were able to undertake the caring roles which fostered intergenerational physical activity. Increasingly, families are becoming more geographically spread (Chan \& Ermisch, 2015); meaning that the performance of the grandparental role through being active together would not always be possible.

The families included in this research form a relatively homogeneous sample of middle class, selfdefined active families, all of which have a two-parent family structure. While this is in itself a strength of the research as it allows us to explore how physical activity is experienced within this group, it could also be considered as a limitation. Given that many of the experiences of physical activity were shaped by middle class aspirations and values, not to mention the economic capital to be able to participate in physical activity, it is likely that families from working class backgrounds would have a very different orientation to physical activity. Similarly, the positive view of physical activity in these families, which is likely related to their social location was conducive to family cultures of physical activity. Therefore, it may be that, in families from different social locations, physical activity may not be considered as a way of doing family. Family structure may also play a role in the transmission physical activity beliefs, understandings and practices as T. Quarmby and S. Dagkas (2010) previously highlighted that while all parents transmitted beliefs to children, children from two-parent families' dispositions were reinforced through participating in physical activity with parents. In other words, two parent families were more able to support a family culture of physical activity. The role of grandparents may also be shaped by understandings of family in 'non-traditional' (e.g. same-sex, lone-parent) families. Thus, further research should explore how other types of family engage with physical activity and what opportunities might exist for creating family cultures of physical activity.

This research brings family life into discussions about physical activity in later life and demonstrates that family is a site of socialisation throughout the lifecourse. It highlights how physical activity practices are cultural and social practices that contribute to family life through performing roles and relationships within families, in the presence of a family culture of physical activity. Thus, physical activity promoters should consider that physical activity cannot simply be imposed on families who might have other ways of doing family without carefully considering how it could become part of their family culture.

\section{References}

Bengtson, V.L. (2001). Beyond the Nuclear Family: The Increasing Importance of Multigenerational Bonds. Journal of Marriage and Family, 63(1), 1-16. doi:10.1111/i.1741-3737.2001.00001.x 
Bourdieu, P. (1973). Cultural reproduction and social reproduction. In: Brown, R., Ed. Knowledge, education and cultural change. London, United Kingdom : Tavistock.

Bourdieu, P. (1977). Outline of a Theory of Practice. Cambridge, United Kingdom : Cambridge University Press.

Bourdieu, P. (1984). Distinction: A social critique of the judgement of taste. Oxon, United Kingdom : Routledge.

Bourdieu, P. (1996). On the family as a realized category. Theory, Culture and Society, 13(3), 19-26. doi: $10.1177 / 026327696013003002$

Braun, V. et Clarke, V. (2006). Using thematic analysis in psychology. Qualitative Research in Psychology, 3(2), 77-102. doi:10.1191/1478088706qp063oa

Cheal, D. (2002). Sociology of family life. Hampshire, United Kingdom : Palgrave.

Chan, T. W. et Ermisch, J. (2015). Proximity of Couples to Parents: Influences of Gender, Labor Market, and Family. Demography, 52(2), 379-399. doi:10.1007/s13524-015-0379-0

Dionigi, R.A., Fraser-Thomas, J. et Logan, J. (2012). The nature of family influences on sport participation in Masters athletes. Annals of Leisure Research, 15(4), 366-388. doi:10.1080/11745398.2012.744274

Grant, B.C. (2001). 'You're never too old': beliefs about physical activity and playing sport in later life. Ageing et Society, 21(6), 777-798. doi:10.1017/S0144686X01008492

Gray, A. (2005). The Changing Availability of Grandparents as Carers and its Implications for Childcare Policy in the UK. Journal of social policy, 34(4), 557-577. doi:10.1017/S0047279405009153

Jenkins, R. (1992). Pierre Bourdieu. London, United Kingdom: Routledge.

Josselson, R. et Lieblich, A. (1995). Interpreting experience (Vol. 3). London, United Kingdom : Sage.

Kwasnicka, D., Dombrowski, S. U., White, M. et Sniehotta, F. F. (2015). Data-prompted interviews: Using individual ecological data to stimulate narratives and explore meanings. Health Psychology, 34(12), 1191-1194. doi:10.1037/hea0000234

McKie, L. (2006). Families, violence and social change. Maidenhead, United Kingdom : Open University Press.

Morgan, D. H. J. (1996). Family Connections: An introduction to family studies. Cambridge: Polity Press.

Morgan, D.H.J. (2004). Risk and Family Practices: Accounting for Change and Fluidity in Family Life. Dans Silva, E.B. et Smart, C., The New Family? (p. 13-30). London, United Kingdom : Sage.

Morgan, D. H. J. (2011a). Rethinking family practices. Hampshire, United Kingdom : Palgrave MacMillan.

Morgan, D.H.J. (2011b). Locating 'Family Practices. Sociological Research Online, 16(4), 14. Repéré à: http://www.socresonline.org.uk/16/4/14.html

Palmer, V. J. (2015). The negotiation of physical activity in three generational families. Unpublished Doctoral Thesis, Glasgow Caledonian University.

Paterson, D. H., Jones, G. R. et Rice, C.L. (2007). Ageing and physical activity: evidence to develop exercise recommendations for older adults. Canadian Journal of Public Health, 98 (suppl. 2), S69S108. doi: $10.1139 / \mathrm{H} 07-111$

Pettee, K.K., Brach, J.S., Kriska, A.M., Boudreau, R., Richardson, C.R., Colbert, L.H., ... Newman, A.B. (2006). "Influence of marital status on physical activity levels among older adults". Medicine and science in sports and exercise, 38(3) 541-546. doi:10.1249/01.mss.0000191346.95244.f7

Phoenix, C. et Sparkes, A.C. (2006). Keeping it in the family: narrative maps of ageing and young athletes' perceptions of their futures. Ageing et Society, 26(4), 631-648. doi:10.1017/S0144686X06004880

Quarmby, T. et Dagkas, S. (2010). Children's engagement in leisure time physical activity: exploring family structure as a determinant. Leisure Studies, 29(1), 53-66. doi:10.1080/02614360903242560 
Ransdell, L.B., Robertson, L., Ornes, L. et Moyer-Mileur, L. (2005). Generations Exercising Together to Improve Fitness (GET FIT): A Pilot Study Designed to Increase Physical Activity and Improve Health-Related Fitness in Three Generations of Women. Women et health, 40(3), 77-94.

Roper, E. A., Molnar, D.J. et Wrisberg, C. A. (2003). "No "old fool": 88 years old and still running. Journal of Aging and Physical Activity, 11(3), 370-387.

Rose, D. et Pevalin, D.J. (2005). The national statistics socio-economic classification: origins, development and use. Basingstoke, United Kingdom : Palgrave Macmillan.

Ross, N., Hill, M., Sweeting, H. et Cunningham-Burley, S. (2005). Grandparents and teen grandchildren: exploring intergenerational relationships. Centre for Families and Relationships [online] Récupéré à:

https://www.strath.ac.uk/media/departments/glasgowschoolofsocialwork/gccs/media 42658 en.pd f consulté le 20 January 2015.

Shaw, S.M. et Dawson, D. (2001). Purposive Leisure: Examining Parental Discourses on Family Activities. Leisure Sciences, 23(4), 217-231. doi:10.1080/01490400152809098

Stevenson, C.L. (2002). Seeking Identities: Towards an Understanding of the Athletic Careers of Masters Swimmers. International Review for the Sociology of Sport, 37(2), 131-146. doi: $10.1177 / 1012690202037002001$

Stone, W.J. (2004). "Physical Activity and Health: Becoming Mainstream". Complementary Health Practice Review, 9(2), 118-128.

Taylor, A. H., Cable, N. T., Faulkner, G., Hillsdon, M., Narici, M. et Van, D. B. (2004). Physical activity and older adults: A review of health benefits and the effectiveness of interventions. Journal of Sports Sciences, 22(8), 703-725. doi:10.1080/02640410410001712421

Tulle, E. (2008). Ageing, the Body and Social Change: Running in Later Life. Basingstoke, United Kingdom : Palgrave.

Wheelock, J. et Jones, K. (2002). 'Grandparents Are the Next Best Thing': Informal Childcare for Working Parents in Urban Britain. Journal of social policy, 31(3), 441-463. doi: $10.1017 /$ S0047279402006657

Email auteur: Victoria.palmer@glasgow.ac.uk

\section{Acknowledgements}

I would like to thank Emmanuelle Tulle for her guidance and comments on this article, and for her assistance with translating the title and abstract. 